\title{
Covid-19: uma agenda de pesquisa em torno das questóes de gênero
}

\section{| ${ }^{1}$ Maria Andrea Loyola |}

1 Instituto de Medicina Social, Universidade do Estado do Rio de Janeiro. Rio de Janeiro-RJ, Brasil (andrea.loyola@terra.com.br) ORCID: 0000-0003-1442-9628

Recebido em: 01/06/2020

Aprovado em: 12/06/2020

Revisado em: 26/06/2020

DOI: http://dx.doi.org/10.1590/S0103-73312020300312

A Covid-19 não apenas nos prendeu em casa e nos obrigou a alterar nossos hábitos, como escancarou aspectos estruturais de nossa sociedade que olhávamos com a devida distância que nossos conceitos permitem. Entre estas, as desigualdades sociais, que já comentei em outro texto (LOYOLA, 2020), e também aquelas relativas aos gêneros, que pretendo levantar agora.

Como viemos observando, a Covid-19 ataca homens e mulheres indiscriminadamente (ainda que estudos epidemiológicos futuros possam apontar diferenças entre eles). Mas não somente isso. Muitos estudiosos, notadamente os antropólogos, definem o gênero como uma construçáo social, não determinada pela biologia, mas pela cultura (MEAD, 1958). Outros levam em consideraçáo as diferenças biológicas entre os sexos para justificar o fato de a mulher, na maior parte das sociedades, ser responsável pelas tarefas reprodutivas e também para justificar a complementaridade dos mesmos. Outros ainda acentuam o aspecto hierárquico da relação, considerando que historicamente a mulher sempre esteve sob a dominação do masculino (GODELIER, 1974; BOURDIEU, 2020).

Tais definições são teoricamente muito complexas e não cabe discuti-las aqui (LOYOLA, 1998). São inúmeras as publicações produzidas pela literatura feminista 
e os efeitos do militantismo feminista, cujo principal alvo tem sido a luta contra o machismo, pelos direitos da mulher e pela igualdade de gêneros (BUTLER, 2003; SHIVA, 2005). A literatura que aborda a homossexualidade ou a homoafetividade nega e confunde essas divisóes tradicionais de gênero (BORRILLO, 2002). O que quero considerar neste momento é o fato de a definição dos papéis masculinos e femininos serem, desde Aristóteles, baseados em oposiçóes binárias do tipo sol x lua, fogo x água, forte x fraco etc., que também não cabe serem elencadas aqui. No momento, gostaria de me restringir à oposição entre a casa e a rua que, como mostra Da Matta (1987), estrutura as relaçôes entre os gêneros na sociedade brasileira.

\section{A casa}

De fato, na divisão sexual do trabalho, historicamente, coube a mulher o espaço delimitado da casa: o cuidado dos filhos, as tarefas e a administração da casa. Ainda hoje, lhe é atribuído o "honroso" título de "a rainha do lar". O homem ficou com o espaço da rua: o trabalho remunerado, o exercício da autoridade e da política. Mudanças sociais e culturais relativamente recentes alteraram em parte essa divisão. Mas em praticamente todas as camadas sociais, com maior ou menor força, ela ainda prevalece. Assim, quando o vírus obriga homens e mulheres a permanecerem isolados em casa, as mulheres não têm dúvidas sobre o que "constitui sua obrigação"ou sobre o que devem fazer: arrumar a casa, cuidar das crianças pequenas (quando há), cozinhar, lavar e passar, decidir o que comer e, não raro, fazer as compras. O que fazem os homens, nessa circunstância? Eis um excelente objeto de pesquisa, a ser desenvolvido pelos cientistas sociais após a onda coronavirus. Algumas evidências podem ser empiricamente observadas:

Nas classes médias principalmente, excetuando o home office que, em grande parte, as mulheres também executam, podemos ver na tevê e nas redes sociais o homem fazendo exercícios, brincando com as crianças, indo ao supermercado, às vezes ajudando as mulheres e, especialmente cozinhando. No isolamento, muitos homens se transformam em exímios, ou não, "chefes "de cozinha - nome pomposo para a execução de uma tarefa que as mulheres sempre executaram rotineiramente. Mais difícil é prever a relação entre os casais, entre si e com os filhos, durante e após a pandemia: afetuosas, cooperativas, conflitivas, com ganho ou perda de comunicação, entre outras. Aumentará ou não o número de separações e divórcios? 
Essas mesmas questôes podem ser colocadas em relação a outras camadas sociais. Para muitas famílias das classes populares (assim chamadas por aqueles que pretendem focalizar, além do corte econômico, os aspectos culturais das camadas de baixa renda), tais relações entre os gêneros não se colocam, uma vez que as famílias dessas camadas integram a maior parte dos $40 \%$ das famílias monoparentais (dirigidas por apenas um dos cônjuges, em sua quase totalidade mulheres) no Brasil. ${ }^{1}$ $\mathrm{O}$ que vemos na tevê e nas redes sociais sobre essas camadas são sobretudo imagens de pessoas nas filas da Caixa Econômica, nas ruas e nos transportes públicos. Sobre a relação entre os casais, temos apenas a informação de que a violência doméstica aumentou com a epidemia.

Em suma, pouco sabemos sobre como ocorrem as relaçóes entre homens e mulheres isolados dentro de casa, e muito menos como ficarão com o final do isolamento. Podemos prever mudanças significativas? Em que sentido? Como se comportam, nessas diferentes camadas, os casais homoafetivos?

\section{A rua}

Na rua, ou seja, fora da casa, o vírus torna visível uma importantíssima diferença entre homens e mulheres: nos países em que as mulheres lideram o país, a pandemia foi mais rapidamente controlada do que naqueles liderados pelos homens. Com exceção do exemplo mais evidente da Coreia do Sul, este é o caso de Alemanha, Nova Zelândia, Taiwan, Noruega, Finlândia, Islândia e Dinamarca. Os homens, no geral, politizaram o vírus visando a seus interesses eleitorais; em alguns casos reconheceram ou foram obrigados a reconhecer sua importância; em outros, como no Brasil, seguem em intermináveis conflitos em torno da melhor maneira de combatêlo, colocando em risco a vida de seus cidadãos, sobretudo os mais vulneráveis.

Podemos nos perguntar se, nesse caso, não se trata também de uma questão de gênero? De fato, historicamente, sempre foi atribuído às mulheres o cuidado com o corpo e com os doentes. Não por acaso,70\% dos profissionais de saúde no mundo são mulheres, enquanto que, de acordo com a União Interparlamentar, em 2018, elas eram apenas dez dos 153 chefes de Estado eleitos. ${ }^{2}$

Essa atribuição da mulher em relação aos cuidados com a saúde tem sido explicada por sua percepção do corpo, sua maior capacidade de empatia e maior sensibilidade, outro atributo definidor do gênero feminino. Já o homem seria mais insensível à doença e mais resistente a reconhecer-se doente, pelo fato de a doença 
significar perda de força, outro atributo definidor do gênero masculino. Mas o que nem sempre foi notado antes do vírus, e que a imprensa internacional vem pondo em relevo, é que, além do combate ao vírus, estas mulheres cuidam também, muito bem e em vários domínios, da coisa pública em seus países.

Artigo recente da colunista Avivah Wittenberg-Cox na revista Forbes considerou essas mulheres "exemplos de verdadeira liderança". Para Geeta Rao Gupta, diretora executiva do Programa 3D para Meninas e Mulheres e membro sênior da Fundação das Naçôes Unidas, as mulheres não têm um estilo de liderança diferente dos homens. Para ela, quando as mulheres estão em posiçôes de liderança, isso traz diversidade à tomada de decisóes, porque elas têm a visão tanto de homens quanto de mulheres, o que contrasta com a postura explosiva e a negação de fatos científicos adotadas por alguns de seus colegas do gênero masculino, como os presidentes dos Estados Unidos e Brasil, Donald Trump e Jair Bolsonaro.

Já para Rosie Campbell, diretora do Instituto Global para Liderança Feminina no King's College London, concorda que "os estilos de liderança não são inerentes a homens e mulheres, mas que devido à forma como foram socializados, é mais aceitável que as mulheres sejam líderes mais empáticas e colaborativas. E infelizmente, há mais homens que se enquadram na categoria narcisista e hipercompetitiva”. Ela acredita que essa característica na liderança masculina "foi exacerbada pela tendência populista na política. Mas, no geral, é algo associado a uma política muito individualista e machista." 3

Por outro lado, as mulheres tendem a conquistar a opiniāo pública ao falar de maneira aberta e transparente sobre os desafios que seus países enfrentam, enquanto os homens tenderiam a colocar a culpa de seus problemas em causas externas, como, no caso do vírus, Trump, Bolsonaro, e também os líderes da Hungria e Israel, atribuindo-o a uma importação da China. Talvez por isso, o até recentemente Ministro da Saúde do Brasil, que adotava essa postura "feminista", eufemisticamente falando, tenha sido demitido pelo Presidente Bolsonaro.

As respostas à crise da Covid-19 foram obviamente diversas, em parte devido às realidades socioeconômicas de cada país e à disponibilidade de recursos — aspectos nos quais o gênero pode não ter influência, como no caso dos países citados, que possuem alto nível de desenvolvimento econômico. Para enfrentar o coronavirus, líderes precisam tomar decisóes difíceis, como bloquear atividades econômicas, o que pode ter um alto custo político no curto prazo, principalmente para países 
enfrentando problemas na economia, como o Brasil. E a meu ver, esta é outra advertência colocada pela expansão da pandemia: o que devem priorizar em suas tomadas de decisóes pessoas que ocupam posições estratégicas de liderança, no presente e no futuro pós-Covid-19?

O dilema que nitidamente esses líderes vêm enfrentando é a falsa oposição entre vida e economia. Categorias profissionais que lidam mais diretamente com os efeitos crescente e universalmente devastadores da epidemia, como médicos, sanitaristas, profissionais de saúde, pesquisadores, estudiosos e administradores mais próximos da população, como prefeitos e governadores, tendem a priorizar a vida, ou seja, o enfrentamento direto do vírus, através do distanciamento e isolamento das pessoas. Naturalmente, isso desorganiza os setores da economia que devem financiar esse isolamento. Assim, os economistas alinhados com os financistas, empresários, comerciantes e produtores em geral, que têm a perder com a suspensão de suas atividades, tendem a ser contra a estratégia do isolamento. Essas posiçóes diferenciadas face à pandemia, que a imprensa brasileira vem traduzindo como uma oposição entre vida x economia, não ocorrem da mesma forma em todos os países, mas são muito acentuadas no Brasil. O que pensam homens e mulheres excluídos sobre tais decisóes?

Responder a esta questão pode ser mais um item de pesquisa sobre o coronavírus para os cientistas sociais. De fato, seria importante conhecer as posições de homens e mulheres face à Covid-19 e às estratégias para combatê-la. Em que medida as diferenças de gênero estariam influenciando suas atitudes face, ou não, ao isolamento? São as mulheres mais cuidadosas do que os homens e mais propensas a seguirem as recomendaçóes dos especialistas e profissionais de saúde divulgadas pelos meios de comunicação? Também neste caso, seria muito importante levar em conta as diferentes camadas sociais.

É possível prever, como os meios de comunicação vêm mostrando, que os setores das camadas médias e altas, que são materialmente equipados com recursos de informática e planos de saúde que lhes facilitam o acesso a hospitais privados, tendem a observar e valorizar o isolamento. O contrário, tudo indica, deve ocorrer nas camadas sociais mais pobres, cujos membros são historicamente desprovidos de recursos econômicos, sociais e de saúde para o enfrentamento da epidemia. E, como a mídia também vem mostrando, a ajuda do governo para compensar as perdas econômicas colocadas pela pandemia não chega até eles com a rapidez necessária, e muito menos àqueles totalmente excluídos, os "invisíveis". 
Sabemos igualmente que essas camadas só dispóem da possibilidade de serem atendidas pelo Sistema Único de Saúde (SUS). E que esse sistema vem sendo sistematicamente sucateado pelo subfinanciamento de suas atividades, tornando-se, portanto, incapaz de fazer face à atual demanda colocada pelo vírus. Tal contexto torna as pessoas mais sensíveis à pregação do governo contra o isolamento e, em consequência, mais dispostas, por necessidade ou não, a também negá-lo.

Seria, pois, importante poder comparar as visōes de homens e mulheres dessas diferentes categorias, que possam nos dar indicações de possíveis, ou não, mudanças nas relaçóes de gênero pós-epidemia. E também se poderemos falar na existência de mudanças de comportamento que contribuíam para a construção de uma sociedade em que a oposição entre economia e vida não se coloque; que o investimento na saúde e na escola pública sejam vistos como prioritários; e que os economistas não sejam colocados como definidores privilegiados dos destinos de uma nação, como vem acontecendo em sociedades como a brasileira.

\section{Considerações finais}

Pelo que conhecemos e podemos observar, tudo indica que mudanças significativas nas relações entre os gêneros, como consequência da pandemia de Covid-19, serão mais fáceis de ocorrer em função do isolamento na casa, onde a possibilidade de atuação individual é maior. $\mathrm{Na}$ rua, fatores político-econômicos e sociais tendem a atuar mais fortemente, sobretudo em países como o Brasil, onde a participação da mulher é muito pequena e nem sempre renovadora.

Judith Butler, em recente artigo sobre a pandemia de Covid-19, afirmou que "a desigualdade social e econômica garantirá a discriminação do vírus. $\mathrm{O}$ vírus por si só não discrimina, mas nós humanos certamente o fazemos, moldados e movidos como somos pelos poderes casados do nacionalismo, do racismo, da xenofobia e do capitalismo" (BUTLER, 2020). Entretanto, como nos mostram os exemplos da gripe espanhola e da Segunda Guerra Mundial, mudanças econômicas e sociais costumam ocorrer após grandes catástrofes globais. E, como mostram as líderes dos países citados, que se distinguiram no combate à Covid-19, um olhar feminino sobre a política poderia contribuir para que essas mudanças venham a ocorrer, acompanhadas por menos desigualdades, em todos os níveis.

De um jeito ou de outro, "nada será como dantes no quartel de Abrantes". 


\section{Referências}

BORRILLO, D. L'Homophobie. Paris: PUF, 2002.

BOURDIEU, P. A dominação masculina. Rio de Janeiro: Bertrand Brasil, 2020.

BUTLER, J. Problemas de Gênero. Rio de Janeiro: Civilização Brasileira, 2003.

BUTLER, J. Sobre a Covid-19: o capitalismo tem seus limites. Disponível em: https:// www.redebrasilatual.com.br/blogs/blog-na-rede/2020/03/judith-butler-sobre-a-covid-19-ocapitalismo-tem-seus-limites/ Acesso em: 4 maio 2020.

DA MATTA, R. A casa e a rua. Rio de Janeiro: Ed. Guanabara, 1987.

GODELIER, M. Um domaine contesté: l’anthropologie économique. Paris: Ed. Mouton, 1974.

LOYOLA, M. A. Basta: reflexões em torno do Covid-19. Physis: Revista de Saúde Coletiva. Rio de Janeiro, v. 30, n. 2, 2020.

LOYOLA, M. A. Sexo e sexualidade na antropologia. In: . A sexualidade nas ciências humanas. Rio de Janeiro: Eduerj, 1998.

MEAD, M. Male and female. London: Menton Book, 1958.

SHIVA, V. Earth democracy, sustainability and peace. Berkeley, CA: North Atlantic Books, 2005.

\section{Notas}

${ }^{1}$ Segundo o IBGE, em 2019, 37,3\% das famílias monoparentais eram chefiadas por mulheres. <https:// www.ibge.gov.br/estatisticas/sociais/populacao/2044-pesquisa-nacional-por-amostra-de-domicilios> Acesso em: 4 maio 2020.

${ }^{2} \mathrm{O}$ mesmo órgão das Nações Unidas informa que o número de mulheres nos parlamentos do mundo subiu apenas $0,5 \%$ em 2015, abaixo do crescimento de anos anteriores, frustrando expectativas de que a igualdade entre gêneros no Poder Legislativo possa ser atingida nas próximas décadas. Disponível em: <https://nacoesunidas.org/participacao-feminina-nos-parlamentos-desacelerou-em-2015-diz-uniao-interparlamentar/>. Acesso em: 4 maio 2020.

${ }^{3}$ Disponível em: <https://www.bbc.com/portuguese/internacional-52376867>. Acesso em: 4 maio 2020. 